TRABALHO DO HOSPITAL S. LUIZ GONZAGA, JAÇANA, SAO PAULO. Chefe de Clinica: Prof. A. LEMOS TORRES

\title{
CONTÁGIO DA TUBERCULOSE NA INFANCIA (*)
}

\author{
DR. MARIO VICTOR LOTUFO \\ (Medico adjunto)
}

\section{HISTÓRICO}

- Bem antes do período hipocrático, os povos pareciam conhecer o carater contagioso da tíșica. Os hebreus proibiam a ingestão da carne de animais que apresentassem o pulmão ulcerado. Mas, é na rica coleção de HrPócrates, comparando a tuberculose à peste e aconselhando a fugir de ambas, que encontramos já alguns dados mais avançados sobre o contágio.

No século de Galena todas as médicos romanos admitiam o contágio da tísica, no ar expirado pelos doentes. Essas noções, aceitas nessa época, vagas no entretanto, se propagaram até a Renascença, quando Fracastoro, de Verona, com a teoria da tísica contagiosa, sedimenta os dados até aí tidos como mais ou menos abstrátos, publi-. cando em 1546, o livro "Dia tísica contagiosa", no qual dá rumo científico e mostra dados patogenicos. Diz ele, referindo-se às molestiás contagiosas e, particularmente à tuberculose, que há necessidade de um doador e de um receptor e que a passagem se faz por meio de pequenos corpúsculos, não visiveis, análogos àqueles que produzem a acidificação do vinagre. Emite assim idéias originais para a época: um homem são, pode se tornar um tísico, si ele vive com um doente. Diz ainda que as vestimentas contaminadas são perigosas até 2 anos após. A tísica, conclue ele, é tão contagiosa como a varíola.

A teoria de Fracastoro foi aceita por todos e medidas de precaução foram postas em uso. MonTANo afirma que uma pessoa poderia se tornar tísica si andasse descalça sobre escarros de tuberculosos e aconselha a não se cuspir nos muros, nas habitações e outros lugares para evitar a propagação da moléstia.

O seculo XVIII se caracterisa pelas medidas profiláticas postas em prática.

(*) Aula dada no Curso de Clinica e de Patologia da Tuberculose Infantil realizado, no Hospital "São Luiz Gonzaga" (Jaçanã) em Junho de 1940. 
Duas proclamações nesse século se tornam célebres, devido ao rigor que elas encerram: a de Fernando IV em 1751 e a de Nápoles em 1782, fazendo obrigatória a declaração da moléstia e a incineração dos objetos que pertenceram aos doentes assim como ainda a desinfecção rigorosa dos domicilios, aplicando-se penas severas aos médicos e enfermeirós que não se submetessem à lei.

No século XIX, novamente o contágio toma incremento. Damos a opinião de PiÉry e Roshem (Historia da Tuberculose): "No século XIX vemos subitamente a luz se fazer simultaneamente sobre todos os pontos e, em menos de cem anos, por em dia mais verdades que os trinta séculos anteriores".

Neste século, 3 nomes se projectam dum modo evidente: LAENNEC (1819), Villemin (1865) e RoberTo Koch (1882) que com suas pesquizas nos esclarecem pontos ainda obscuros.

LAENNEC, com a hereditariedade, para ele, causa primeira da tísica; Villemin com suas experiências em animais e $\mathrm{KoCH}$ descobrindo o germen causador do mal.

Dessa época para_cá, até nossos dias, inúmeros estudos teem sido feitos, esclarecendo ainda mais tão importante problema.

\section{FONTES DE INFEÇÃO}

Encontramos essas fontes no homem e no animal.

Fonte humana: Como dissemos ao relatarmos o histórico, de há muito já se conhecia, ou melhor se suspeitava do contágio inter-humano, mas só se firmaram esses conceitos após as experiências de VILlemin e a descoberta do bacilo por КосH.

Encontramos o material contagiante principalmente no tuberculoso pulmonar. As fézes de tuberculosos intestinais, a urina de tuberculosos renais, as secreções de fístulas de tuberculoses osseas e articulares ou lupus; com dificuldade podem produzir infecção, porque elas com alguma higiene podem ser tornadas inocuas. Praticamente, portanto, devemos considerar o tuberculoso pulmonar como a maior fonte contagiante.

No contágio de origem humana, tão grande percentagem de transmissão encontramos no seio da família que o dividimos em familiar e extra-familiar.

Contágio familiar: Quasi a maioria dọs A. A. está de acordo nas suas estatísticas em apontar os paes como os causadores principaes da transmissão.

As observações de Schram, em Oslo, são interessantes nesse sentido. Desde 1918, a direção de Higiene manda que todo o filho de tuberculoso seja submetido à reação à tuberculina, achando-se:

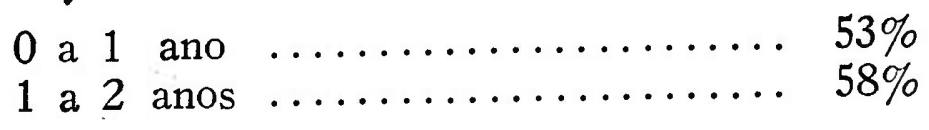


de 3 a 7 anos vae-se elevando progressivamente chegando a $80 \%$ na edade de 7 a 8 anos.

LeON.Bernard em 128 creanças, filhos de tuberculosos, achou 95 tuberculino-positivos.

A contaminação no seio familiar torna-se bem patente pelo fato de que basta afastar os recem-nascidos, para que cresçam sãos. MERCIER observou que 20 meninos retirados do contágio de paes tuberculosos e colocados num orfanato, "viviam em bôa saude, enquanto 10 irmãos que continuaram no seio da familia vieram a falecer. Cомву salva $97 \%$ de creanças nascidas de tuberculosos, pondo-as no campo, enquanto que $50 \%$ das que permanecem na convivencia familiar sucumbem.

O contagio é tanto mais fatal quanto mais contínuo for ele, e é por isso que as mães, devido ao seu intimo e constante contáto com os filhos contaminam muito mais do que os paes ou qualquer outra pessoa e si ambos estiverem doentes a percentagem se eleva ainda mais.

SQUire nos mostra, em estatísticas, que houve contaminação pela mãe em $34,4 \%$, pelo pae em $31 ; 8 \%$ e por ambos em $39,45 \%$. LEROUX e Grunberg (1912) em 142 familias dão a seguinte estatistica: um só progenitor tuberculoso, a contaminação se fez em cerca de $32 \%$ dos filhos e em ambos os progenitores alcança a $41,6 \%$.

Em 144 lactantes, em estatistica feita em França, achoù-se que a contaminação foi motivada 95 vezes pela mãe, 20 vezes pelo pae, 20 vezes pelo pae e mãe juntamente, 3 vezes pelos parentes que 'habitavam a casa e 6 vezes pelas creadas que se ocupavam das crianças.

No serviço do Hospital "São Luiz Gonzaga" (Jaçanã) de 1934 a 1938 inclusive, foram examinadas 1824 crianças de 0 a 14 anos, que acusavam contagio. Dessas crianças apresentavam cuti positiva 774 ou seja $65,3 \%$ e tinham tuberculose atíva 343 ou seja $28,9 \%$.

Considerando unicamente os casos com contagio familiar (pai, mãe e parentes), teremos 1.128 crianças das quais 755 (67\%) apresentavam cuti-reação positivas e destas, cerca de 338 com tuberculose ativa, dando a alta cifra de $44,6 \%$, cabendo à mãi, a maior percentagem de infecção nessa forma de tuberculose, cerca de $57,5 \%$ do total dos 755 casos.

Gravidade do contágio familiar: O contágio é tanto mais fatal quanto mais contínuo for ele. COMBe fazendo estudos sobre isso, acha tambem que a mãi é a maior responsavel, vindo em ordém decrescente os pais, os irmãos mais velhos, depois os avós, outros parentes, creados, etc.

Dois fatos devem ser levados em conta na gravidade do contágio da criança: a continuidiade desse contágio e a idade da criança.

A tuberculose das crianças de peito, de origem materna é muito mais grave porque a contaminação se faz dum modo muito mais repetido. WALSTEIN relata em estatística feita sobre 29 crianças contaminadas pela mãi, na qual 22 morreram antes de 1 ano e 6 antes de 2 anos. 
Mecanismo do contágio no seïo familiar: A criança se inféta com prodigiosa facilidade. Os seguintes casos nos mostram isso. PeyreR e DiETL apresentam uma observação em que alguns minutos de contágio foram "suficientes para que a criança se contaminasse. FinkeLSTEIN, relata um caso em que apenas algumas horas foram necessarias, UnVericht, um caso de 1 dia e Roger e Garnier um caso de 2 dias de duração: Debré em lactantes poude provar a duração do contagio nos seguintes casos: menos de 15 dias, 2 casos, de 15 a 30 dias, 3 casos, de 1 a 3 mêses, 24 casos, de 1 a 6 mêses, 14 casos, de 6 a 12 mêses, 21 casos, de 1 a $1 \frac{1}{2}$ ano, 13 casos e de $1 \frac{1}{2}$ ano e mais, 2 casos.

Debré com isso, deduz que um lactante que viva 3 mêses com sua mãi tuberculosa, dificilmente escapa ao contágio e LEON BERNARD ạcha que ao cabo de 6 mêses a tuberculisação é quasi certa.

O contágio no seio familiar póde-se fazer de mil maneiras e com um mecanismo facil de se compreender, principalmente em se tratando de mãi tuberculosa, devido á vida íntima que leva perto dó recem-nascido.' Sua permanencia ao lado da criança é quasi constante e nos seus gestos, os mais banais, não faz outra cousa sinão levar germes ao contáto do filho'. Prova os alimentos, assopra a comida para esfriar, enxuga a boca da criança com seu lenço bacilif̣ero, beija-a constantemente, etc.

Demine cita um caso de uma governante com carie tuberculosa no maxilar e que chegou a infectar 3 crianças, pelo vicio de experimentar alimentos. REICLE cita outro caso instrutivo, de uma mulher que contaminou 3 recem-nascidos, por insuflar ar, boca a boca, para a respiração artificial, vindo as 3 crianças a falecer.

Quando fóra do berço, época em que os alemães chamam de "toca tudo", muitas vezes é a propria criança que procura sua contaminação, principalmente pelo costume de tudo levar à boca. BALDWIn em 18 mãos de crianças habitando residências de tísicos, encontrou em 11, o bacilo $(61 \%)$.

Para resumir o que acima dissémos, daremos a seguir o que escrevem LeON BeRnard e Debré, estabelecendo verdadeiras leis a respeito do contágio:

I - As causas de contaminação e a gravidade da doença estão em relação proporcional com o potencial do contáto.

II - A infecção é tanto mais grave quanto mais prolongada for ela.

III - O contáto é tanto mais perigoso quanto menor for a criança.

IV - Uma criança separada do fator contagioso sobreviverá si a doença não aparecer após um mês dessa separação.

Contágio pelo leite materno: O contágio pelo leite materno pódese fazer pela tuberculose da mama que é extremamente rara, cerca de $0,5 \%$ das doenças do seio e, pelo proprio leite, o que é muito contraditório. Fede, De Michele e outros, pesquizando bacilos no leite, de 
mulheres tuberculosas, mas sem lesão da mama, nunca o encontraram. Rapin e Fortineau, em 13 pesquizas obtiveram só uma positiva. No entretanto, o japonês YAMADA e seus colaboradores servindo-se do método da anti-formina, acusam a fantástica cifra de $85 \%$ de leites bacilíferos; mas é de supor que houve erro nessas pesquizas, porquanto outros investigadores, tais como WANG e COONLEY, usando o mesmo processo e examinando 450 amostras de 28 tuberculosas, não conseguiram nenhum resultado positivo. Outros autores encontraram em minima percentagem. De modo que com raridade é possivel a eliminação pelo. leite de mulher, dizem PéHu e Dufourt.

Contágio extra-familiar: De muitos modos tem a criança facilił. dade para se contagiar fóra da familia. Esse contágio pode-se fazer pela poeira dos logradouros muito frequentados pelos doentes, em hospitais, créches, orfanatos, escolas, etc. Às vêzes esses lugares oferecem quasi que as mesmas condições ambientes do domicílio familiar, devido ao constante contágio da criança. Assim são as créches, hospitais, escolas, etc. Schloss observou que em uma créche, de 18 crianças, 13 reagiram à tuberculina e procurando a causa, a encontrou numa. enfermeira muito bacilífera.

No contágio escolar, não parece ser o contágio de aluno para aluno, o mais importante. Deve-se buscar a fonte bacilífera entre os professores. Estatisticas de Delobel nos mostram 2,5\% e de Mery 5\%. de doentes contagiantes entre os professores.

ETIENNE BERNARD nos apresenta diversas observações interessantíssimas a respeito do contágio extra-familiar e entre elas está uma de um professor e que por ser muito instrutiva passamos a relatar.

Trata-se de um professor, com a idade de 25 anos, que foi examinado a 19 de Março de 1937, sendo que nesse mesmo dia ainda, administrava suas lições numa classe de meninos de 9 a 10 anos. As lesões que apresentava eram bi-laterais, havendo uma vasta caverna do lobo superior direito, outra no lobo inferior desse mesmo lado e uma infiltração de todo o lobo superior esquerdo. Exame de escarro positivo para bacilo de Koch; cerca de 15 por campo.

E de se notar que desde 1930 vinha esse paciente sendo examinado. É assim que, em 1930, sofre um primeiro exame médico, mas não acompanhado de exame radiológico. Em 1932, exerce as funções de professor. Em 1933 apto ao serviço militar é incorporado num regimento de infanteria, tendo sido feito um exame radioscopico; tira uma radiografia que acusa lesão no apice direito, sendo então reformado.

Em Janeiro de 1934, procura novamente o professorado e após exame medico, que lhe aconselha 3 mêses de repouso, findo os quais é readmitido sem outro exame. Em Julho de 1934 casa-se. Em 1936 seu estado vae peorando progressivamente e a 19 de Março de 1937 submetido a exame médico fica constatada a gravidade do caso sendo afastado do serviço, tendo até esse dia exercido suas funções sempre em contáto com as crianças. 
Passa Étienne Bernard, médico que o examinou, a relatar a serie de desastres provocados com sua tuberculose aberta, não só no seio da família como tambem no decorrer de seu professorado.

$1^{\circ}$ ) Em sua família, passou suas férias de inverno 1936 ao lado de sua irmã, que tinha um filho de 3 anos e meio; esta criança morreu de meningite tuberculosa a 9 de Fevereiro de 1937.

$\left.2 .^{\circ}\right) \mathrm{Na}$ escola, este professor estava encarregado duma classe de meninos de nove a dez anos. Os dados recolhidos pelo doente e pelo enfermeiro escolar são os seguintes:

Durante o primeiro semestre 1936-1937: anemia.

a) $\mathrm{O}$ menino $\mathrm{Br} \ldots$ teve de deixar a escola por cansaço geral e

b) O menino Mal... deixou a escola em Novembro e foi necessário ser ehviado para a montanha. Ravoire.

c) O menino M... foi encaminhado para o Sanatório de La

d) O menino Bar... morreu a 18 de Janeiro de 1937 com meningite tuberculosa. $\mathrm{O}$ inquerito aberto a esse respeito prova que não havia tuberculose na família e tudo faz crer que fosse o professor o. contagiante.

A classe desse professor contava 37 alunos. Após licença, 32 alunos foram ao dispensario onde o Dr, P. LAFosse procedeu à cuti-reação. 29 tiveram a cuti positiva, cerca de $90 \%$. Foram submetidos ao exame radioscopico. Entre os que apresentavam cuti positiva, 11 tinham o hilo aumentado, arborescente, com nodosidades de contornos apagados. Os outros nada apresentavam.

Crianças de outra classe, mas com a mesma idade foram examinadas sob o ponto de vista da cuti-reação. Sobre 13 crianças, 9 tịveram cuti negativa, 4 cuti positiva, seja $30 \%$.

Outras classes examinadas, deram resultado em média de $30 \%$. Esses dados nos permitem verificar o carater francamente anormal da taxa de $90 \%$ revelada na classe do professor tuberculoso.

Entre nós, Paulo Minervini, em um recente trabalho intitulado: "A reação de von Pirquet numa Escola Mixta Rural", que foi enviado å V Congresso Pan-Americano de Tuberculose, relata um caso mais ou menos semelhante.

O autor acima citado estudando a cuti-reação na cidade de Rio Claro (São Paulo), encontrou uma positividade de cerca 30\% entre os escolares de 7-12 anos, e fazendo para termo de comparaçã̇o a cuti em Escolas Rurais, encontrou numa delas a percentagem de positividade bastante elevada, $48,4 \%$. Verificando a percentagem nos varios grupos de idade encontrou $80 \%$ entre os de 7 anos e predominando tambem a positividade no $10^{\circ}$ ano escolar. A topografia das reações positivas na sala de aula permitiu a descoberta da fonte de contagio: os casos positivos agrupavam-se quasi todos em torno da mesa da professora. Esta era uma tuberculosa cavitaria, tendo pelo menos seis mêses de molestia e de contáto com as crianças. 
Casos como esses existem por aí em quantidade. Alguns por negligência, outros devido aos proprios doentes, que sabedores de seu estado, procuram oculta-lo por receio de perder o emprego ou outro motivo qualquer, tornam-se verdadeiros e perigosos disseminadores.

Contágio entre crianças: O contágio de uma pessoa adulta para uma criança se faz dum modo relativamente facil como vimos acima. Interessante seria saber até que ponto é possivel o contágio entre as proprias crianças, si seria nulo ou si idênticas medidas profiláticas como nos adultos teriam de ser postas em prática; felizmente podemos dizer desde já que isso não sucede.

FLorencio BAzAN ha pouco mais de um ano escreveu sobre isso, fazendo um apanhado geral sobre esse assunto, que passamos a relatar, citando pesquizas, tais como as de Poúlsen, Wallgreen, Lewin OpITZ, etc., que muito bem estudaram essa -questão.

A tuberculose primaria muito mais frequente e sobretudo as formas benignas, sem sintomatologia, nem radioscopias evidentes, só diagnosticaveis pelas reações à tuberculina eram consideradas formas fechadas, não contagiantes, portanto não merecedoras do isolamento. Mas, mesmo nessas formas, de fáto benignas, viu-se, que com as pesquizas sistemáticas do bacilo no suco gástrico, que. ele é eliminado com frequência.

Com estes conhecimentos produziram-se divergências entre os pediatras sobre a importância prática desses novos dados e ainda qual o papel do contágio entre esses meninos. Esse assunto que tanta celeuma trouxe foi amplamente discutido no Congresso de Pediatria Internacional celebrado em Roma em Outubro de 1.937.

Duas correntes se formaram: dum lado os que sustentam a possibilidade do contágio em todos os casos (Poulsen, Opitz, Enged, LANGer, Eliasberg, Lessí, etc.) ; de outro os que negam, dizendo que umá cousa é demonstrar a presença do bacilo no súco gástrico e outra a possibilidade de transmissão e contágio (Hamburger, PrIeSel, KruGER, WALLGREEN, Debré, etc).

Continuando na serie de considerações a respeito de tão importan$\because$ problema, passam os AA. em revista esses fatos, encarando a forma da moléstia, idade da criança, etc. Deixam comtudo de considerar a tuberculose terciária do menino adulto, apresentando bacilo no escarro e cuja contagiosidade é tão grande quanto a do adulto, estudando a princípio a tuberculose prìmária, mais frequente na criança pequena.

A tuberculose primaria pulmonar aféta 2 formas diferentes de acordo com a extensão de suas lesões e de sua evolução: 1) a forma grave, evolutiva, caseosa ou caseo-cavernosa e a 2) a forma benigna com ou sem localisações diagnosticaveis.

A primeira, a forma grave, se observa sobretudo nos primeiros tempos da vida, na lactância ou nos primeiros anos que se seguem. E um processo infiltrativo, invasor, com sinais radiológicos nítidos, temperatura alta, tosse e expectoração bacilífera. Estas crianças deglutem o catarro. A tosse é em geral escassa e fraca, dado a gravidade do 
caso e idade da criança. A tuberculose caseo-cavernosa da criança é bacilífera e contagiante por vézes. Porem as caracteristicas de gravidade que apresenta a afecção, e por atacar a criança pequena que não sabe tussir, nem escarrar, as probabilidades do contágio são pequenas.

Forma benigna da tuberculose primaria, nos interessa pela sua grande frequência nas formas de tuberculose infantil e grande percentagem de achado do bácilo no suco gástrico. Os trabalhos de Levin, Opitz, Philipson, Wallgreen, etc., demonstraram este fato, nesses casos antes vistos como tuberculose benigna fechada. A porcentagem de positividade da lavagem gástrica oscila entre 50 e $80 \%$.

Cuidados especiais devem ser tomados nessa pesquiza de lavagem gástrica. Ficou demonstrado ser necessária a persistência da iñvestigação, isto é, sendo preciso, diante da negatividade das primeiras lavagens, fazer sua pesquiza mais vêzes. As estatísticas de Poulsen e LEVIN mostram esta asserção:

\begin{tabular}{|c|c|}
\hline & Poulsen \\
\hline 1. ${ }^{\mathrm{a}}$ lavagem $\ldots .$. & $77 \%$ \\
\hline 2. ${ }^{\mathrm{a}}$ lavagem $\ldots \ldots \ldots \ldots$ & $91 \%$ \\
\hline 3. a lavagem & $96 \%$ \\
\hline 4. ${ }^{a}$ lavagem & $98 \%$ \\
\hline 5. a lavagem & $100 \%$ \\
\hline
\end{tabular}

A pesquiza do bacilo deve ser feita precocemente, pois a positividade é tanto mais alta quanto mais recente for a lesão, porque depois vae havendo o processo de cicatrisação e o bacilo vae se tornando raro. A séguinte estatística de WALLGREEN com 49 crianças com tuberculose primária nos esclarece isso.

Estas crianças foran examinadas de 3 em 3 mêses, diminuindo progressivamente a porcentagem dos positivos:

Tbc. recente $\ldots \ldots \ldots \ldots \ldots \ldots$

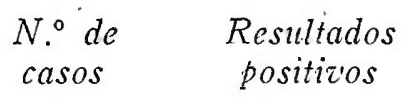

49

49

31

19

11

33

49
31
19
11

$\%$ positivos.

Exame ulteriores

3 mêses após ...............

G mêses após $\ldots \ldots \ldots \ldots \ldots \ldots . .$.

9 mêses após $\ldots \ldots \ldots \ldots \ldots \ldots$

12 mêses após $\ldots \ldots \ldots \ldots \ldots$...... $67,3 \%$.

Após 12 mêses nos casos que puderam ser controlados temos a baixa de 67,3 para $18,1 \%$.

A disparidade dos achados, entre os diversos autores, talvez ache aí sua explicação. Poulsen em 200 crianças em idade pre-escolar, com reação à tuberculina positiva, encontrou só $16,3 \%$ de bacilo positivo, ao passo que Philipson encontrou em 97 crianças em idades semelhantes e afectadas de tuberculose recente, 59\%. A idade tem influência. São os lactantes que dão as mais altas cifras, cerca de 80 a $90 \%$, e isso ain- 
da pelo mesmo motivo exposto acima, isto é, por apresentarem lesões mais recentes, e principalmente mais vezes formas exuberantes.

As publicações dos seguintes autores: Poulsen, Levin, Opitz, Wallgreen, Philipson nos mostram isso:

Lactantes $\ldots . \ldots . \ldots \ldots \ldots \ldots \ldots \ldots \ldots$

Crianças pequenas $\ldots \ldots \ldots \ldots \ldots \ldots \ldots \ldots$

Edade preescolar $\ldots \ldots \ldots \ldots \ldots \ldots \ldots \ldots$.

Edade escolar

\begin{tabular}{ccc}
$\begin{array}{c}\text { N.o de } \\
\text { examinados }\end{array}$ & $\begin{array}{c}\text { Resultados } \\
\text { positivos }\end{array}$ & $\%$ \\
126 & 99 & 78,5 \\
106 & 72 & 67,9 \\
105 & 69 & 65,7 \\
169 & 78 & 46,2 \\
\hline 506 & $\frac{13}{318}$ & $\frac{62,8}{20}$
\end{tabular}

A extensão das lesões tem sua maxima importância, tanta importância que o açhado positivo tem grande valor prognostico (Kurt Klare). Wallgreen e Philipson em casos recentes, mas sem a existência de lesões radiográficas encontraram suco gástrico positivo de 10 a. $22 \%$ das crianças examinadas e quando existiam lesões radiográficas a percentagem foi de 73 a $85 \%$.

Depreende-se dessas citações estatísticas acima que grande é,a percentagem das crianças que eliminam bacilos, apresentando tuberculose aberta, pelo menos durante certo período, portanto aptas a contagiar. Mas, diz, J.. BAzAN, que uma cousa é eliminar bacilos e outra é transmití-los. Para aclarar este ponto, pesquizas e experiências foram feitas. Em primeiro lugar figura a investigação de bacilos nos objecțos manejados pelas crianças.

LEVIN em 39 crianças que continham bacilos no suco gástrico, colocou uma especie de máscara bucal de gaze e deixou varias horas; corțou em pedaços, lavando-os em solução fisiológica, e injetando posteriormente em cobaias. Todos os resultados foram negativos.

WALLGREEN pesquizando o b. nas chupetas de 7 crianças com ida- de de 2 a 12 mêses, notou a nulidade dos resultados.

LANGER em brinquedos de celuloide, pertencente a uma criança tuberculosa descobre o bacilo.

Os autores russos Balander, Triousse e Klebanova praticaram estas mesmas experiências em crianças com diversas formas de tuberculose, submetidas à cura sanatorial. Suas conclusões são as seguintes: as crianças com formas infiltrantes de tuberculose, eliminam bacilos no ambiente (máscaras de gaze, cortinas, etc) e podem contaminar a criança sã. Devem ser afastadas e tratadas em estabelecimentos especiais.

Resumindo, pode-se dizer que na maioria dos casos os objetos tocados pelas crianças com tuberculose benigna não contêm bacilos em condiçōes de infetar a cobaia. Contra isso fala o caso de LANGER e dos autores russos.

Bacilos de Koch no ar expirado durante os periodos quintosos de tosse: dum modo geral a criança pequena não tem tosse intensa, porem si sobrevêm tosse convulsa pode haver saída de bacilos para o ar am- 
biente, o que provou Wallgreen em 1933 durante uma epidemia de tosse convulsa; em 11 crianças com suco gastrico positivo e tuberculose benigna, 3 eliminaram bacilos para o ar ambiente durante o áto da tosse. Levin, com as mesmas experiências, em 6 crianças obteve 1 caso positivo e procurando o bacilo na poeira das salas que encerravam crianças com tuberculose benigna, sem tosse, mas com suco gástrico positivo, notou resultados negativos.

Desta serie de investigações conclue-se: as crianças com tuberculose benigna, que habitualmente não contaminam a cobaia, podem contaminá-la quando uma tosse violenta facilita isto. Encontram-se essas eliminações nos coqueluchoides e nas crianças com tráqueo-bronquite. E prudente pois afastá-las das crianças sãs.

Observações de caráter clínico: Ha muitas observações de caráter clínico de crianças com tuberculose benigna, suco gástrico positivo e que conviviam com outras crianças sãs, e muitas vezes no mesmo 1eito, não as contaminando. Estas observações clínicas, que são banais e que todo o medico poude já ter comprovado, diz Bazan, demonstram que estas crianças com tuberculose benigna e bacilos no suco gástrico, não constituem, sem duvida, um perigo para as crianças sãs. Sob o ponto de vista prático, pelo menos, não devem ser consideradas contagiantes e portanto não precisam ser separadas das crianças com reação tuberculinica negativa.

WALLGREEN se expressa a respeito, na seguinte fórma: "Por nossa parte afirmamos, jamais termos tido ocasião de observar um só caso de infecção, que se possa imputar de forma induvidavel a uma criança com tuberculose primaria benigna".

\section{CONTÁGIO ANIMAL}

O contágio animal raramente se faz pelo contato direto do animal para o homem, é verificado sobretudo devido á absorção do leite crú ou mal esterelizado procedente de animais tuberculosos, em sua maior parte o gado bovino.

Para se ter a idéia de como a tuberculose é frequente no gado bovino, basta citar estatísticas feitas em 1928, no Matadouro de Berlim. De 49.235 vacas abatidas, 26.376 , portanto $53.5 \%$, foi descoberta tuberculose, e $5 \%$ tinham tuberculose generalizada.

$\mathrm{Na}$ seguinte estatística vemos a porcentagem de vacas infectadas em diversas partes do globo:

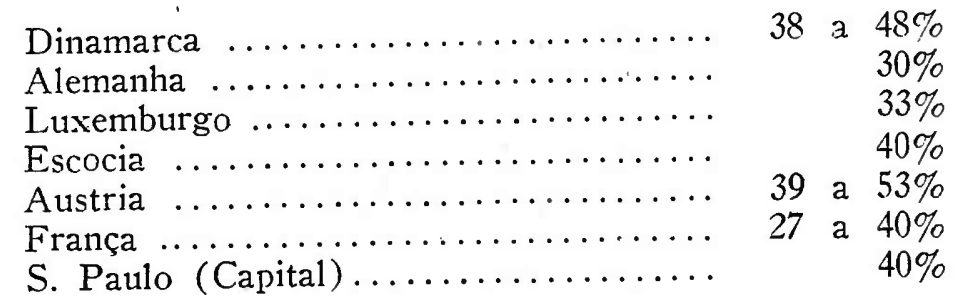

Qual o mecanismo da passagem dos bacilos ao leite? 
Na maior parte dos casos parece tratar-se de tuberculose do úbere. $5 \%$ das vacas que reagem à tuberculina sofrem de mamite tuberculosa. Mas basta muitas vêzes estarem varios animais ou um somente numa granja para que todo o leite se contamine, porque costuma-se fazer a mistura total do leite para a distribuição ao consumo público.

De 1921 a 1928, Bruno LANGe em pesquizas feitas em 3.219 amostras de leites, achou 243 positivas, isto é, $7 ; 5 \%$. Osterman em um litro de leite de uma grande empreza, achou 1.000.000 de bacilos. Nos últimos anos, devido aos cuidados tomados pelas autoridades competentes, tem diminuido o numero de positivos, dum modo geral.

Novamente vem a baila, si vacas tuberculosas, mas tendo o úbere são, deixariani passar bacilos ao leite. Alguns negam. Outros admitem, como por ex. BANg e Titze que injetando bacilos por via endovenosa em vacas de lactação, viram ao cabo de 3 semanas aparecerem bacilos no leite e em un animal houve eliminação até 144 dias após. Segundo Gedacht, de 14 a $19 \%$ das vacas, sem tuberculose do úbere eliminam bacilos pelo leite.

Leite de cabra e de outros animais como jumenta não oferecem o mesmo perigo, dizem PÉHu e Dufourt, porque raramente estes animaes adoecem.

Derivados do leite: Manteiga, nata, queijo, kefir. Na manteiga acha-se por, vezes quantidade grande de bacilos. PÉTRI achou em pesquizas $32 \%$ de manteigas contaminadas. Ostermann, Eber, Cornet, cerca de 10 a $12 \%$. Benide, em Breslau encontrou $15 \%$. SchroeDER e COTTON, após 99 dias, em manteigas bem conservadas, não acidificadas, acharam bacilos virulentos. A nata póde conter até 100 bacilos por grama. Os queijos conservam por semanas e mêses bacilos virullentos.DoANe inoculando pedaços de queijo em cobaias, conseguiu tuberculizá-las até 200 dias após o fabrico.

No nosso meio, ha pesquizas feitas quanto ao leite e derivados, e entre elas a do Dr. Alexandre de Mello em artigo publicado na Revista da Industria Animal. Em São Paulo, para o gado leiteiro do municipio, a reação à tuberculina foi de $40 \%$. Existe cerca de 10.000 cabeças, portanto 4.000 infectadas, cujo leite era antes distribuido crú aos habitantes. Destas 4.000 cabeças, cerca de 5 a $10 \%$ seriam portadoras de tuberculose aberta e da mama 2 a $4 \%$.

Dr. Alexandre De Mello pesquizando o bacilo em 100 amostras de leite oriundas da Capital achou 30 positivas (30\%).

$\mathrm{Na}$ manteiga, fez pesquizas semelhantes, em amostras das feiras e armazenis, não achando nenhuma amostra positiva. Mas tem que se notar a esse respeito que a manteiga não deriva do leite da Capital, onde o indice de infecçã̃o é de 40\%, mas sim deriva do leite do interior e Estados vizinhos onde o gado é menos infetado, cerca de $2 \%$ somente.

Carnes: O músculo, em si, não contêm bacilos, mas os gânglios de seu interstício podem ser contagiantes. As víceras, fígado e baço, principalmente, podem apresentar lesões.

Outros animais: Outros animais podem ser computados como transmissores da tuberculose, mas com raridade. Temos a tuberculose 
do cão, gato, papagaio, canário, galinha. Contaminados alguns deles pelo homem, como acontece com o. cão e o gato, tornam-se posteriormente fontes de contágio. No caso de aves, como a galinha, LöwenSTEIN incriminou a passagem do germen atravéz do ovo crú em dois casos em crianças, nas quais foi descoberto o bacilo aviário nas lesões.

Importância comparada das fontes do contágio humano e bovino: Koch e BeHring foram os dois extremos na questão do contágio de origem animal. Косн negando, BEHring afirmando. Hoje em dia não mais se admitem duvidas. O bacilo bovino é contagiante. WoLLERS, citado por BRUNo LANGE, em crianças de 5 anos, achou que $22,5 \%$ da tuberculose era produzida por bacilo bovino e em crianças de 5 a 16 anos 22,3\%; estes factos são importantes diz BRUNo LANGE.

Diversas comissões foram nomeadas para verificar a veracidade dos factos e a sua frequência. Ficou constatado ser o tipo bovino perigoso. Clinicamente é dificil suspeitar a origem duma lesão, porque quer a produzida por $\mathrm{b}$. bovino, quer a produzida por $\mathrm{b}$. humano são semelhantes. Temos que recorrer ao laboratório.

Dos diversos estudos e pesquizas depreende-se a seguinte percentagem relativa ao tipo bovino:

\begin{tabular}{|c|c|c|}
\hline Comissão inglêsa & $17,5 \%$ & \\
\hline Comissão alemã $\ldots \ldots \ldots \ldots \ldots$ & $10 \%$ & \\
\hline Spronck $\ldots \ldots \ldots \ldots \ldots \ldots$ & $10 \%$ & \\
\hline Oeckler & $10 \%$ & \\
\hline Stepfenhagem & $12 \%$ & \\
\hline De Besch (Oslo) ............. & $11 \%$ & \\
\hline Mitchel (Edimburgo)......... & $90 \%$ & (adenites) \\
\hline Fraser $\ldots \ldots \ldots \ldots \ldots \ldots \ldots$ & $60 \%$ & (osteo-art.) \\
\hline Gordon (EE.UU.). & $33 \%$ & \\
\hline
\end{tabular}

PARK pesquizando o bacilo bovino nos diversos orgãos encontrou:

\begin{tabular}{|c|c|c|c|}
\hline . & $0-5$ anos & 5 a 16 anos & $\begin{array}{l}\text { mais de } \\
16 \text { anos }\end{array}$ \\
\hline Tuberculose pulmonar & 4,1 & 0 & 0 \\
\hline Tuberculose ganglionar .. & 58 & 36 & 3,6 \\
\hline Tuberculose abdominal & 59 & 46 & 22 \\
\hline Tuberculose meningéia & 13,6 & 0 & 0 \\
\hline Tuberculose osteo-articular .... & 0 & 7,3 & 3,5 \\
\hline Tuberculose generalizada $\ldots \ldots \ldots$. & 23 & 40 & 2,7 \\
\hline
\end{tabular}


Localisação do bacilo bovino na criança. Pesquizas efetuadas pela comissão alemã :

Tuberculose pulmonar ................ 0

Tuberculose dos ganglios do pescoço ........ 40,7

Tuberculose dos ganglios do mesenterio ...... 51

Tuberculose meningéia ................. 10,3

Tuberculose generalizada $\ldots \ldots \ldots \ldots \ldots \ldots, 23$

Apezar destas estatísticas demonstrativas, alguns AA. tentam negar o contágio pelo bacilo bovino e dizem ser ele müito raro. WeBER, na Alemanha, em 360 casos encontrou somente 2 vezes. Na Italia, pesquizas semelhantes e mesmos resultados.

PeHú e Dufourt dizem: "Em resumo, não é necessario exagerar o perigo do leite de vaca e seus derivados alimenticios, nem devemos negá-lo de um modo sistemático. Segundo os trabalhos e documentos publicados no mundo inteiro, podemos fixar aproximadamente de 5 a $20 \%$, segundo os paizes, a proporção dos casos de tuberculose infantil de origem bovina. Na França, a tuberculose de origem bovina continúa sendo extremamente rara”.

Ha uma observação interessante e de ordem geral: A medida que a criança cresce, vae diminuindo paulatinamente o numero de casos por b. bovinos. No adulto, são eles muito raros. A passagem do bacilo bovino para o humano não está demonstrada. Séria ele menos virulento e não atacaria o homem, mais resistente do que a criança? Sofreria de fato uma transformação? Nada ao certo póde-se dizer ainda.

\section{DAS VIAS DE PENETRAÇÃO DO BACILO}

O bacilo póde, por todas as vias, infetar um organismo. Algumas são raras: cutânea, mucosas faciais, via ocular. Outras vias são de-predileção: respiratoria e digestiva.

Iremos ver cada uma dessas vias, iniciando-se o estudo pela via respiratória, a mais importante delas todas.

Via respiratória: A predominância da localisação pulmonar sempre chamou a atenção dos estudiosos. Para alcançar o alveolo, onde ele se assésta para produzir a lesão, tem o bacilo que atravessar o filtro das vias aéreas superiores. As mucosas da traquéia, brônquios, laringe, são muito resistentes à infecção, e não são atravessadas pelos bacilos como nas outras mucosas, conforme observação de $\mathrm{H}$ ÜвSCHMANN. Deve-se saber, a priori, que a maioria dos bacilos são aí retidos, pela extrutura e outros fatores e no entanto, as lesões se originam em regra no pulmão e, para que isso se dê, é necessário que o bacilo alcance o alveolo pulmonar, como dissemos, poucos bacilos bastando para dar formação ao fóco. Alguns autores acham mesmo, como BRUNo LANGE, que um só bacilo seja suficiente.

O bacilo pode ser aspirado pelos pulmões logo ao ser expelido pela pessoa doente por meio das goticulas e no estado de secura, veículado 
pelas poeiras. Esses dois estados serão a seguir estudados e experiências e conclusões relatadas.

Infecção por gotículas frescas: O primeiro autor a estudar a possibilidade da infecção por gotículas foi FLÜGGE em 1897. Chega a essa conclusão após experiências com bacilos prodigiosus. Notou ele que uma corrente de ar com velocidade de 4 metros por segundo, batendo na superficie líquida duma emulsão de bacilos prodigiosus, com incidência de $45^{\circ}$ era capaz de desprender gotículas contendo germens. Isso tambem acontece, diz FLÜGGE, quando falamos, tossimos, espirramos, isto é, a passagem brusca do ar através da árvore respiratória é capáz de arrancar do muco, aí existente, gotículas contendo bacilos.

FLÜGGE com seus assistentes, continuando suas pesquizas relata a experiência de um de seus assistentes Dr. LARCHTSCHENKo, que pondo na boca uma diluição de bacilos prodigiosus e falando depois em frente a meios de cultura, a diversas distâncias, viu que gotículas com bacilos prodigiosus aí iam ter.

Essas experiências levaram FLÜGGE a formular sua teoria do contágio da tuberculose pelas gotículas. Mas, no entretanto, restava saber si essas gotículas ou perdigotos contendo bacilos tuberculosos contagiavam de fáto o ser humano. Chaussé a esse respeito diz que FLÜGGE não deu pessoalmente, nenhuma prova suficiente, com o fim de demonstrar essa possibilidade, tendo sido praticadas somerite pelos seus assistentes, mas duma maneira pouco convincente.

Que ha expulsão de gotículas e essas contêm bacilos é fáto demonstrado desde FLÜGGE. Cerca de 40 a $50 \%$ dos tísicos expelem gotículas contaminadas. BraUning achou que $30 \%$ das gotículas pequenas continham bacilos em numero médio de 20 bacilos.

Temos que distinguir duas espécies de gotículas: as bucais e as bronquiais. As bucais sã̃o mais grossas, contêm epitélio, bactérias e raras vêzes bacilos. As bronquiais são mais finas, não tem epitélio, mas sim leucocitos, fibrina, muco e são portadoras de bacilos; pódem conter até 2.300 . Podem atingir de $2,5 \mathrm{~mm}$. a $10-15$ micra. O numero de bacilos vae decrescendo conforme o tamanho da gotícula, tendo aquelas de 10-15 micra em geral apenas um só bacilo segundo HippKe. Quanto mais bacilífero for o tísico, maior número de gotículas contendo bacilos,

As observações todas, concordam que a disseminação das gotículas se faz em média até 80 centimetros podendo chegar, no entretanto, até a 1 metro. Essas gotículas principalmente as maiores se depositam após alguns minutos, porem as mais finas podem boiar no ar e rem sempre possuem bacilos como dissemos, a não ser quando a secreção for muito rica. ICKERT acha que essas gotículas podem permanecer no ar até 9 horas.

Seriam essas gotículas ou perdigotos respiraveis? Segundo BRUNo LANGE, ChAUSSÉ e outros, dificilmente penetram até o pulmão e isso pela extrutura e disposição das vias aéreas superiores, sendo preferentemente detidas. $\mathrm{O}$ ar inspirado sóbe, a principio verticalmente. corre ao longo do assoalho do nariz e, chegando à faringe, tem que se 
refletir para baixo. Com o rodamoinho do ar, principalmente nos lugares de reflexão, as gotículas se fixam nas paredes do nariz, faringe ou qualquer outra parte da parede das vias aéreas superiores.' Temos ainda que considerar a atração da mucosidade aí existente.

A seguir relataremos experiências realizadas em animais, comprovando até que ponto é possivel a contagiosidade por meio das gotículas ou perdigotos.

CḢaussé, na França, foi um dos que mais se ocupou com o estudo do contágio por meio de gotículas'e poeiras. Publicou de 1914 a 1916, artigos baseados nas suas experiências em animais.

Chaussé estudou em primeiro lugar o teor de bacilos existentes na saliva e no escarro. Na saliva achou por vezes bacilos, mas em numero muito pequeno e isso somente era possivel quando o muco bronquico ia ter à boca nos indivíduos em geral muito bacilíferos. É necessário considerar que as particulas salivares respiraveis, pesam cerca de $1 / 300.000$ de miligramos, e as menores ainda, mais facilmente inhalaveis atingem de $1 / 10.000 .000$ a $1 / 20.000 .000$ de miligramos, por consequência a grande maioria das particulas salivares, e as respiraveis são desprovidas de bacilos.

Chaussé em suas experiencias, emprega em primeiro lugar aparelhagem onde faz passar corrente de ar com diversas velocidades, fazendo-a chegar na superfície dum recepiente ou mesmo mergulhando um tubo no escarro, fazendo então borbotagem. O escarro era bacilífero até 90.000 bàcilos por miligramo. Por meio de um tubo de saída, as gotículas iriam ter a uma caixa grande onde estavam as cobaias. Cerca de 3 horas a 3 horas e meia após, retirava as cobaias e as sacrificava mêses depois, quando algum tubérculo já pudesse ter se desenvolvido.

A velocidade do ar que passava pelo escarro ia desde 15 metros até 85 metros por segundo. Com a velocidade de 35 metros, foram submetidas à experiencia 34 cobaias e apenas uma delas ficou infeccionada. Abaixo de 35 metros nenhuma. Com velocidade de 64 a 85 metros, 6 cobaias ficaram infeccionadas em 18 que foram submetidas. Com isso, verificou Chaussé a necessidade de velocidade de 35 metros por segundo ou mais para se desprenderem gotículas capazes de infeccionar a cobaia.

Numa 2:a série de experiências, verifica a inhalação diréta, pela cobaia, do ar expirado pelos tísicos, no momento da tosse. Tomou uma caixa como das experiências acima, de capacidade de 126 litros e 79 cobaias foram submetidas em 8 vêzes. 12 tísicos dos máis contagiantes, tussiram 1.570 vêzes. Após isso, as cobaias eram retiradas e depois do tempo de observação, sacrificadas. Houve apenas uma cobaia contaminada. Conclue CHAUssé, que o contágio à tuberculose, pelas partículas líquidas, não póde ter lugar sinão raramente e com a maior dificuldade possivel.

Dois anos após, repéte CHaussé novamente suas experiênciąs, mas em condições um pouco diferentes. Diminuiu a capacidade da caixa: 86 litros ao envez de 126 litros, onde as cobaias recebiam as 
gotículas è a caixa era tambem mais baixa, de modo que a corrente de ar passava pelo focinho dos animais, tendo maior "chance" de contaminação. Submeteu 152 cobaias à experiência, obtendo 31 positivas ou seja $20,39 \%$, ao passo que da vez primeira somente 1 se contaminára.

CHAussé que a principio negára a formação de gotículas, dizendo que a velocidade do ar no aparelho respiratório humano não ultrapassava de 25 metros, portanto insuficiente para arrancar gotículas da secreção brônquica, refazendo as experiências e medindo novamente - a velocidade do ar ao nivel da laringe humana, verificou que a velocidade alcançava a 45 metros por segundo no momento da tosse, capaz portanto de arrancar gotículas bacilíferas e era no laringe, ao nivel das cordas vocais que a velocidade alcançava o seu máximo. Conclue com suạs experiências que o contágio humano, por meịo de gotículas, está definitivamente estabélecido, mas as gotículas inalaveis, já por si diminutas, escasseiam na grande diluição do ar ambiente, tornando ainda mais raro o contágio por esse meio. De fáto, na experiência em que ás cobaias estavam encerradas em caixa de 86 litros de ar, obteve 31 casos positivos entre 152, mas bastou que a capacidade da caixa passasse de 86 para 126 litros, portanto uma pequena diluição para que apenas uma cobaia se contaminasse dentre 79 que foram submetidas. Nos milhares de litros de ar ambiente, portanțo, vemos a escassez percentual das gotículas bacilíferas respiraveis e a raridade com que isso possa suceder. Daí se concluir, que as gotículas, como fator de contágio na tísica tem seu principal papel depois de seu deposito, após secas e sob a forma de poeiras, principalmente as grandes gotículas com mais de 2.000 bacilos, quando novamente veiculam no ar, e isso porque as gotículas se depositam em todo o lugar, assoalho, paredes, roupas, objétos e sua destruição torna-se praticamente impossivel quasi, o que não acontece por exemplo com o escarro que se torna menos perigoso do que as gotículas, nesse caso, porque pelo seu volume visivel póde ser destruido.

BRUNo LANGE não acredita no contágio inter-humano pelas gotículas e diz que são anti-naturais as experiências feitas, como acontece com as de CHaussé, dizendo que não são as gotículas que infetaram as cobaias, mas sim o pó procedente da desecação das gotículas. Essa desecação podia-se fazer até no proprio pêlo do animal. Acha ainda BRUNo LANGe que as gotículas menores que podem conter bacilos mẻdem de 15 a 20 micra e não podem ser inaladas até os alveolos, parando nas vias bronquiais, ao contrário das substâncias poeirentas̄, como carvão por ex., que atingem. 5 a 10 micra alcançando o alveolo. Conclue BRUno LANGE: "a infecção pela poeira seria a forma regular na vida diaria”.

Simon e RedekER, em seu livro Tuberculose Infantil, dizem que em primeiro lugar está a contaminação pelo bacilo da poeira, podendose comtudo se fazer raramente por gotículas.

Infecção pela poeira: A primeira experiência foi feita em 1869 por Villemin, insuflando poeira de escarros secos na traquéia de 
coelhos, conseguindo tuberculizá-los. TAPPEINER em 1877, pulverizando escarros secos, com a ajuda de um empregado de laboratorio, tentou tuberculizar cães, não só conseguindo infetar os animais, como tambem seu ajudante, que veio a falecer. CORNET com varredura de tapetes com escarros secos, infeta 46 cobaias das 48 que submetera à experiência.

Numerosas outras experiências foram feitas e chegou-se a con-.. clusão que a poeira contendo bacilos é contagiante e, por vêzes, apresenta-se de uma finura tal que contem em seu meio bacilos isolados. que flutuam no ar. As poeiras grosseiras visiveis, não chegam até o. alveolo e se depositam facil e rapidamente.

E necessario que se fale, desde já, quanto à quantidade de bacilos necessarios para dar formação ao cancro de inoculação, como é chamada a lesão inicial. BRUNo LANGE regeita a hipótese de que para. as gotículas são necéssários poucos bacilos para infetar um pulmão e no caso das poeiras, devido a menor virulência, seriam necessarios. muitos bacilos, como afirmam muitos AA. Acha BRUno LANGE que um só bacilo é às vêzes o suficiente e faz a seguinte experiềncia: utilizando-se de quantidade de poeira que só continha um bacilo ou numero escasso deles, obteve em animais a infeção por inalação.

CHAussé pratica, para demonstrar o contágio pelas poeiras, uma outra série de experiências. As primeiras foram feitas com a permanência de cobaias em salas de tísicos. Deixava durante 34 dias, cobaias encerradas em uma gaiola a um metro de altura.' Após esse tempo, eram retiradas e permaneciam vivas ainda mais 18 dias antes. de serem sacrificadas, tempo suficiente para que os tuberculos fossem vistos a olho nú. Foram empregađas 76 cobãas, tendo se tuberculizado cerca de 30 , portanto $39,47 \%$. O numero de cobaias infetadas: nesse ambiente foi grande, diz CHAussé e reportando-se isso para o ser humano, que respira de 100 a 250 vezes mais ar do que uma cobaia, aumentam ainda mais as probabilidades de infeção nesse ser, e diz: "teoricamente um ser humano não póde coabitar com um tísico, sem realizar um tubérculo pulmonar cada dia." Isso teoricamente, como diz Chaussé, querendo mostrar a probabilidade dos bacilos. atingirem diariamente o pulmão. Conclue, esse autor, defendendo a. tese de que a tuberculose humana "se respira".

A seguir verificou CHAussé a virulência das poeiras dos quartos: de tísicos. Recolheu a poeira em placas de Pétri contendo agua distilada e as colocou, em numero de 18 , sobre a mesa, debaixo da cama. e na parede a 80 centimetros da cabeceira do doente. Após 4 dias. retirou-as e inoculou seu conteudo em cobaias. Das 18 , sete se mostraram virulentas, provindas dos três lugares onde foram colocadas as placas.

A poeira contagiante provem, como vimos, após essa serie de experiências e pesquizas, dos mais variados lugares: dos lenços, lençóes, roupas as mais diversas, da barba, do corpo do doente, do cabelo, mãos, etc. Lavando cabelo de doente e inoculando o líquido da lavagem em cobaias, achou CHaússé 2 vêzes em 4 , bacilos virulentos. 
Bacilos tuberculosos em escarro no assoalho das habitações, vivem muito tempo. Pela via respiratoria, inalando-os, a virulencia vae até 25 dias e, si inocularmos na cobaia, vae até 2 mêses ou mais. Em roupas, 3 semanas depois do doente as ter usado, ha bacilos virulentos.

Contágio nos veículos e lugares públicos: Os trabalhos de CoRNET e de alguns outros autores mostram que as poeiras das ruas dum modo geral não são virulentas. HṬRT pesquizando em varredores de rua, a morbilidade, achou que se comparava a de outros profissionais. KunZ com 20 amostras de poeiras de rua, não poude pôr em evidência o bacilo, pois não podemos comparar o ambiente da rua, no contágio de uma pessoa, com um quarto, por ex., de tuberculoso onde a quantidade de bacilos é grande. Temos ainda de considerar a vitalidade do germen. Ele é destruido nas ruas com muito mais facilidade do que nas habitações. Em sólo seco não passa de alguns dias. Nas habitações com certo gráo de humidade póde atingir mêsẹs e finalmente nas habitações de tísicos, os bacilos são constantemente renovados pelos doentes. No entretanto, ha certos lugares, fóra das moradias, que condicionam ambiente mais ou menos semelhante. Escolas, hospitais, créches, certos lugares públicos, veículos, etc. PrausSNITZ recolhendo 20 amostras dos vagões da linha Berlim-Meran, frequentada por doentes, achou 5 positivas, portanto este ambiente era perigoso. Pesquizas semelhantes em outras linhas deram resultados. negativos.

O perigo das poeiras dos lugares frequentados pelo público não é, por certo, nulo, mas é geralmente fraco comparado àquele das poeiras dos locais ocupados pelos doentes.

Infeção pela via digestiva: A infeção pela via digestiva está demonstrada ser possivel, mas não com a intensidade que descrevem certos autores, como por ex. Calmette. Diz Chaussé, si o leite que é o veículo por excelencia da contaminação por via digestiva, fosse contagiante, seria o bezerro o mais frequentemente contaminado, e isso não acontece como demonstrou CHAussé em pesquizas feitas em 35.000 vitélos, resultando que a morbidade tuberculosa éra de 1 por 400 do total.

A possibilidade da criança ingerir bacilos, em pequenas quantidades, existe, diz BRUno LANGE, principalmente na idade do brinquedo. De acordo com experiências em animais, essas pequenas quotas de bacilos, só raramente conduzem à infeção, porque as mucosas digestivas possuem certa resistência à penetração, do bacilo, mas grandes doses de bacilo em regra produzem infeção. Essas grandes doses só pelo leite crú. infetado, ou falta de higiene em contato com tísicos.

WEBER julga necessario 10 miligramos de bacilos para o bezerro. A comissão inglêsa conseguiu com $1 / 100 \mathrm{mg}$. a lesão em bezerros. Na cobaia, que é muito sensivel, ha necessidade de 1 a $10 \mathrm{mgrs}$. de bacilos.

Chaveau en 1868 fez experiência sobre carneiros, fazendo ingerir produtos tuberculosos provocando lesões somente nos ganglios tra- 
queo-brônquicos e pulmões, sem que houvesse lesão alguma no tubo digestivo. Outros autores demonstraram a mesma cousa, ficando patente a possibilidade do bacilo atravessar o tubo digestivo sem deixar vestígio. A passagem se faz mais facilmente si ministrarmos os bacilos com matérias gordurosas. Por esse meio, Nicola, após 3 horas encontrou bacilos na cisterna de Pecquet.

ROYER e BINET emitem a opinião seguinte: a abșorção no intestino se faz por duas vias: a venosa e a linfática. Na venosa são os albuminas e hidratos de carbono que, indo pela veia porta, alcançam o fígado. Na linfática são os graxos e daí passam ao canal torácico para desembocar na veia sub-clavia esquerda, chegando assim ao coração direito, onde são lạnçados na pequena circulação sendo o pulmão o primeiro orgão que encontram em seu trajéto. Os bacilos que o acompanham; aí podem ser retidos devido à fina rede capilar sanguinea. Calmette admite esta via, mas acha que são os leucocitos que transportam os bacilos, sendo eles tambem retidos na fina rêde capilar.

ENGEL, após 6 horas, sacrificou uma cobaia que ingerira bacilos e os achou no pulmão. Em todas as experiências feitas nunca se achou no pulmão, diz BRUno LANGE, pela ingestão de alimentos contaminados, a formação do complexo primario correspondente ao do pulmão humano.

Argumentos anátomo-patológicos: Na mesa de autópsia ao lado da grande frequência da tuberculose dos ganglios bronquiais, vemos a raridade das lesões primarias nos ganglios mesentéricos. GHoN em 184 casos encontrou o cancro intestinal 3 vezes apenas. $\mathrm{Na}$ grande guerra foi verificada a entrada típica pela via digestiva, nas tropas sēnegalêsas, onde as autópsias acusavam $10 \%$ de tuberculose abdominal pura.

Infeção pelas mucosas das cavidades faciais: O achado de bacilos e lesões tuberculosas nas amígdalas não é de todo raro, servindo esse orgão como porta de entrada. Shuster em 100 amígdalas de indivíduos mortos de tuberculose encontró a lesão específica na amígdala sem tuberculose pulmonar em $12 \%$ e com tuberculose pulmonar em $40 \%$. A deglutição e gotículas de FLÜGGE podem ser as causadoras desta lesão. Não está provado que haja comunicação linfática cervical com os gânglios traqueo-bronquicos, de modo a dar passagem direta aos bacilos, alcançando o pulmão.

Dentes cariados: Autores norte-americanos dão importância aos dentes cariados como porta de entrada, devido terem achado bacilos aí. Experiências feitas em macacos, inoculando bacilos na polpa dentaria, mostraram a disseminação dos bacilos que alcançavam posteriormente o pulmão.

Infeção pela péle: É rara. É conhecido o caso de LeLorr de uma criança de 6 anos que apresentou uma lesão primitiva ao nivel de uma ferida que foi tratada com saliva por uma creada tuberculosa. 
Combé em 25 anos observou 3 casos de infeção primitiva na péle.

E notório o aparecimento de lesão tuberculosa em crianças, nas quais após a circuncisão é feita a sucção da ferida pelos rabinos, por vezes tísicos.

Finalmente, vamos, para encerrarmos a citação das portas de entrada do bacilo, dar as vias: ovular, espermatica e transplacentária.

Transmissão ovular: Ha um só caso citado na literatura, por SiTZEFREY, dum óvulo contendo bacilo, mas é sabido que um tal óvulo não poderia chegar â maturação e, muito menos, germinar. Portanto, esta hipótese ovular, fica afastada.

Transmissão pelo esperma: O espermatozoide como o óvulo, é evidente, si contivesse bacilo não possuiria propriedades germinativas. No esperma, ha muitas observações comprobantes da existência de bacilo, provindo da tuberculose genital e entre elas a observação de FoÁ. Mas é fato observado que os filhos, nascidos de pais com tuberculose nos genitais, nada apresentam. Esta via, como a ovular, deve ser afastada.

Transmissão transplacentária: A transmissão pela placenta é possivel e foi verificada. Considerava-se a placenta como um filtro perfeito, mas NATHAN LARRIER demonstrou o contrário, e outros autores vieram confirmar.

$\mathrm{Na}$ raça bovina segundo VALLËE, em 700 vacas tuberculosas, só uma houve que transmitiu a tuberculose ao féto durante a gestação.

$\mathrm{Na}$ raça humana após as investigações de PeHu, Chalier, Whitmann e Greene "os casos indiscutiveis do contagio transplacentário, tratavam-se quasi sempre de mulheres afetadas de tuberculose avançada ou granúlica". No ultimo estádio da tuberculose, os bacilos podem invadir o organismo chegando até a placenta, podem contaminá-la e chegar ao féto. Outras vêzes ha contaminação do féto sem que se encontrem lesões visiveis na placenta.

Convêm àinda notar, que nos casos de tuberculose intra--uterina, o féto morre durante a gravidês, ou, em casos mais favoraveis, morre algumas semanas após seu nascimento. A autópsia revela lesões granúlicas difusas com predomínio hepático. 